This is an electronic reprint of the original article. This reprint may differ from the original in pagination and typographic detail.

Author(s): Koivula, Merja; Hännikäinen, Maritta

Title: Building children's sense of community in a day care centre through small groups in play

Year: $\quad 2017$

Version:

Please cite the original version:

Koivula, M., \& Hännikäinen, M. (2017). Building children's sense of community in a day care centre through small groups in play. Early years: An International Journal of Research and Development, 37(2), 126-142.

https://doi.org/10.1080/09575146.2016.1180590

All material supplied via JYX is protected by copyright and other intellectual property rights, and duplication or sale of all or part of any of the repository collections is not permitted, except that material may be duplicated by you for your research use or educational purposes in electronic or print form. You must obtain permission for any other use. Electronic or print copies may not be offered, whether for sale or otherwise to anyone who is not an authorised user. 


\section{Building children's sense of community in a day care centre through small groups in play}

Merja Koivula and Maritta Hännikäinen

Department of Education, University of Jyväskylä, Jyväskylä, Finland

Corresponding author: Merja Koivula, Department of Education, University of

Jyväskylä, P.O. Box 35, 40014 University of Jyväskylä, Finland. Tel. +358 408054657

E-mail: merja.e.koivula@jyu.fi 


\title{
Building children's sense of community in a day care centre through small groups in play
}

\author{
This study examines the process through which children build a sense of \\ community in small groups in a day care centre. The study asks: how does \\ children's sense of community develop, and what are its key features? Data were \\ collected by applying ethnographic methods in a group of three- to- five-year old \\ children over eleven months. The results show that children's sense of \\ community developed through three stages. In the first stage, it evolved gradually \\ through experiences in joint play. In the second stage, stable friendships were \\ formed and strengthened in play. In the third and final stage, sense of community \\ was fully established and children's emotional bonding was strong, manifesting \\ itself in affective and physical closeness, sharing and caring, and togetherness.
}

Keywords: sense of community; day care centre; play; friendship; togetherness

\section{Introduction}

In recent years, sociocultural theories have had a strong impact on our views of children's learning and development. One outcome of this has been an emphasis on the importance of the different communities that exist in children's daily lives and learning (e.g. Bath 2009; Hedegaard et al. 2012; Rogoff 2003). By focusing on exploring these communities, especially children's immediate physical and social contexts, insights can be gained into children's experiences (Dockett, Kearney, and Perry 2012; Williams, Sheridan, and Sandberg 2014), and into the social, cognitive and emotional significance of their community membership (Bath 2009; McMillan and Chavis 1986; Rogoff 1998).

To date, to the best of our knowledge, little is known about how young children develop their sense of community in day care groups or about children's sense of community in general. However, some work has been done on sense of community 
community in general. Sense of community among toddlers has been explored especially from the perspective of the formation of social relationships and joint activities (e.g. Engdahl 2011; Løkken 2000). According to Løkken (2000), toddlers construct their peer group mainly through physical and non-verbal means, whereas among children over the age of 3 , interaction is characterised by greater use of verbal means and collective ways of acting. Research on the construction of community by children aged 3 to 5 , however, seems to be lacking. We seek to address this gap in the literature by exploring how young children's sense of community develops in a Finnish day care centre.

In the daily life of young children, more work has been done on themes related to sense of community, such as belongingness (Bath 2009; Joerdens 2014; Over 2016; Stratigos, Bradley, and Sumsion 2014), we-ness (Fernie, Kantor, and Whaley 1995; Kantor, Elgas, and Fernie 1993), togetherness (Hännikäinen 2003, 2007; van Oers and Hännikäinen 2001) and friendship (Corsaro et al. 2003; Greve 2009; Ladd 2005). In the research literature, the concepts of belongingness, we-ness, togetherness and friendship have not been clearly distinguished. In light of the literature mentioned above, we-ness and togetherness, referring to the feeling of emotional interconnectedness between children, seem to refer to the same phenomenon and thus can be considered synonymous. Feelings of emotional interconnectedness can often also be considered to include friendship. "Friendships are relationships based on mutual support, affection, and companionship" (Howes and Lee 2007, 268). However, togetherness (we-ness) does not necessarily include friendship: instead, togetherness is linked to the child's experience of emotional closeness during a certain activity (van Oers and Hännikäinen 2001). 
Belongingness can be understood not only as comprising relationships among children, but also as belongingness to a community or to a certain environment. As emphasised by Over (2016), in relationships, a central feature of belonging is long-term commitment by the child. This notion is also present in the concept of sense of community, which depicts belongingness, membership, and emotional connectedness to a certain group or community (McMillan and Chavis 1986), and which is developed through participation in the activities of that group or community.

In sociocultural approaches to child development, learning is seen as occurring through the opportunities created by adults and peers in the different communities that children are members of (e.g. Dockett, Kearney, and Perry 2012; Fleer 2006; Hedegaard et al. 2012; Rogoff 2003), including the day care centre. Different social networks, including family, peer groups and other group contacts, are an integral part of young children's lives from early on (Hay, Payne, and Chadwick 2004). Being able to participate in the different activities of these groups, however, requires the motivation to engage and interact with others (Over 2016). From a sociocultural perspective, children are viewed as gradually appropriating the knowledge needed to function in their communities (John-Steiner and Mahn 1996; Rogoff 2003). In the day care centre this includes, for example, knowledge of the rules and norms, allowed ways of interacting, group boundaries and what constitutes socially acceptable behaviour (Hännikäinen 2005). Each community is always socially constructed, which explains why it is both an outcome of a process and yet constantly changing. Yet, research too often focuses on the complicated relationships between individuals and communities and neglects examination of the processes linked to the formation and development of different kinds of communities (Linehan and McCarthy 2001). There is also a need to find out how communities shape the individual and how, reciprocally, each individual child 
transforms the communities they participate in (Lewis, Enciso, and Moje 2007). To approach this goal, it is first necessary to explore the development of sense of community.

\section{Sense of community}

The concept sense of community can be understood as a process in which the members of a community engage in social interactions and contribute to the good of the community (Bess et al. 2002), yet it has proven to be difficult to define (Bath 2009). In this study, we have adopted McMillan and Chavis's (1986) definition as our point of departure. This definition involves four key elements: membership, influence, integration and fulfilment of needs and shared emotional connection.

Membership refers to belongingness and personal relatedness. The notion of membership also includes the group's boundaries, which define who belongs to the group and who does not (McMillan and Chavis 1986). In practice, children enact and construct membership through participation in joint activities (Fernie, Kantor, and Whaley 1995). These activities create possibilities and resources through which they can attain peer group membership (Bath 2009), and so develop more stable play groups, friendship groupings and core groups. At the same time, peer group participation enables children to construct their collective peer culture and practice social and communicational skills (Corsaro 2003). Participation in a peer group is not always a simple and straightforward process. It requires gaining access to and membership of the group, leading to the phenomenon of inclusion, but is also impeded by hierarchies and exclusion (Fernie, Kantor, and Whaley 1995; Hedegaard et al. 2012). Children have the need to signal affiliation through togetherness, but at the same time they create rules, rituals and routines as well as discourses and specific activities to maintain their group's 
boundaries and exclude others (Fernie, Kantor, and Whaley 1995; Ladd 2005). These practices regulate children's mutual activities and relationships (Hännikäinen 2005).

Day care centres have collective rules, rituals and routines in their daily activities that similarly contribute to children's peer culture both on the interpersonal and community/institutional planes (Corsaro and Molinari 2000; Rogoff, 1998; Williams 2001) and lay the foundation for the social organisation of the peer group. Children have a tendency to form different short-term play-based groups, more stable friendship groupings and core groups within the peer group as a whole (see Fernie, Kantor, and Whaley 1995; Kantor, Elgas, and Fernie 1993). These groups differ in their cohesiveness, salience, display of cultural knowledge and influence: in short-term play groups, these features may be weakly manifested, but in core groups all four characteristics are displayed at a high level (Kantor, Elgas and Fernie 1993). In core groups, the group boundaries are strong, membership is restricted and the group develops its own, distinctive culture, with specific ways of interaction, specific activities and a specific orientation towards play materials (Kantor, Elgas, and Fernie 1993).

The second element of sense of community, influence, pertains to each group member's importance to the other members, making a difference to the group, and to the meaning of the group to its members (McMillan and Chavis 1986). As Sawyer (2001) states, children's encounters and joint activities in their peer group results in learning. At the same time as each individual learns social skills in interaction with others, the whole group learns how to behave as a group on the interpersonal and community/institutional planes (Rogoff 1998). This includes, for example, appropriating the peer culture through learning shared rules and norms, ways of interaction and specific activities, and the social structure that is constructed and 
maintained in the group over time (Hännikäinen 2005; Williams 2001). Influence in the child group seems to occur at two levels. First, at the level of community, each community or child group influences its members through collective rules, norms and the culture of the group (Williams 2001). Second, each child also contributes to the development of the group. This occurs especially through participation in joint activities and the ability of individual group members to advance and co-construct joint play through expressing emotions, wishes, and goals (Hännikäinen 2003).

The third element, integration and fulfilment of needs, is linked to the feeling that membership of the group contributes to the fulfilment of the members' needs (McMillan and Chavis 1986) on the personal and interpersonal planes (Rogoff 1998). In a peer group, children's reciprocal social relationships become central. Affective involvement manifests itself in children's friendships, which are based on mutual support, affection and companionship (Howes and Lee 2007). In addition to making friends, the ability to join a peer group and experience membership and togetherness in the group is an important task when joining a day care centre (Fernie, Kantor, and Whaley 1995; Hännikäinen 2003; Ladd 2005). Through joint activities and interaction, children learn different skills and at the same time contribute to one another's learning (Rogoff 2003). Fulfillment of the child's needs in the peer group context in day care centres occurs through the formation of friendship relations, which are emotionally significant for the child's development, and through participating in meaningful play activities (Hännikäinen 2007).

The fourth element of sense of community, shared emotional connection, refers to commitment and the feeling that the members of the group share a history and have similar experiences (McMillan and Chavis 1986). Therefore, shared emotional connection can be understood as a feeling of togetherness. Togetherness includes the 
view that children want to be engaged in their shared activity even in the case of disagreements: they are willing to struggle and resolve any problems that may arise (van Oers and Hännikäinen 2001). Children display togetherness by engaging in joint play and physical proximity, having fun together and emphasizing their mutual bonds and belongingness (Hännikäinen 2003, 2007), which in turn may contribute to the development of sense of community.

To summarize, the research literature strongly emphasizes the dynamic and evolving nature of children's peer groups. As Rogoff $(1998,2003)$ states, participation in a community is fundamentally connected to learning. Learning in a community can also be seen as an active, reciprocal process. When children appropriate the culture of a community, they also modify their peer culture (Hännikäinen and Rasku-Puttonen 2010; Rogoff 2003). In this process, each peer group develops unique features, including shared meanings, expectations and rituals within the overall peer culture (Kernan, Singer, and Swinnen 2011).

\section{Method}

This study, as a part of a larger project (Koivula 2010), examines the process through which children build a sense of community in small groups in a day care centre. The study asks: how does children's sense of community develop, and what are its key features?

Participants in this ethnographic study were a day care group of 22 children aged between three and five. The group, named "The Raspberries", comprised two children aged three, 15 aged four and five children aged five. The group had been formed at the beginning of the autumn term, in August. At that time most of the children were unfamiliar with each other. 
It is possible, through observations, to capture children's intensive engagement with each other and their efforts to become part of their peer group (Højholt 2012). The data collection began at the very beginning of the autumn term. The observations focused on the children's activities, interaction and peer relationships and were carried out by the first author. One play situation was selected for each observation, and the observations, varied in duration from one to 20 minutes, depending on the content of the children's play. To capture the contextual and interactional features of the children's play activity, observational data were mainly collected in the form of video recordings (6 hours) but also included written notes (57 pages) and audio tape recordings (1.5 hours). Data were gathered at intervals in order to be able to track the process of development of the children's community. In total, 29 days of observational data were collected over 11 months.

Social relationships, characterised by physical and affective closeness, between children and a researcher commonly develop during an observation period. This necessitates careful reflection by the researcher on her role with regard to the ethics and objectivity of the data collection. Such reflection was implemented throughout the present research process.

In this study, the researcher's role was that of an interested observer of children's play (Johansson 2011). A positive and confidential relationship between the children and the researcher was established by the latter showing interest in the children's play, talking with the children, being friendly and honest with them, and gaining their trust (see e.g. Dockett, Einarsdottir, and Perry 2009), and also by visiting the group before the data collection in order to get to know the environment and the children themselves. 
Other ethical issues were also considered from the very outset of the study. All the children of the group were invited to participate in the study. Informed consent was obtained from the municipal authorities and the teachers and parents. The children's assent was initially sought by talking about the nature, purpose and goals of the study with them, and by explaining that participation was voluntary. All the children agreed to participate and consented to the researcher's request to be present and observe their play, and in each play situation, the children's consent was confirmed by asking their verbal permission to be observed and video recorded. On some occasions, despite their verbal consent, the children's bodily movements and facial expression subsequently revealed discomfort and reluctance about being observed. In these situations, the children's cues were respected by terminating the observation session. Generally, the children seemed to like being observed and video recorded.

In addition, the children's rights to anonymity, self-determination, privacy, confidentiality, dignity, fair treatment and protection from discomfort or harm were respected in the reporting and dissemination of the study. All names were replaced with pseudonyms, and any other information that might enable individuals to be identified was removed. The strategies employed reflected the ethical principles and standards of The Finnish Advisory Board on Research Integrity.

\section{Analysis}

The data were analysed through qualitative content analysis, utilizing the four elements of sense of community (McMillan and Chavis 1986) and reflecting upon the three planes of sociocultural activity (Rogoff 1998). After all the data had been transcribed, the transcripts were carefully studied and coded. The unit of analysis was a meaningful episode in the course of play, including verbal or nonverbal communication. The 
individual episodes detached from the data varied along with the duration of moments and situations relating to sense of community (see McMillan and Chavis 1986). The coding of the data was abductive: the codes and categories emerged from the data, but the theoretical and conceptual frame of the study also influenced their labeling and interpretation. After coding the whole data set, categories were formed and then analysed in detail. The categories included, for example, boundaries, friendships, influence, rules, needs, sharing and caring, shared experiences and togetherness. The second phase tested how far these categories corresponded to the four elements of sense of community presented by McMillan and Chavis (1986). It was found that the elements functioned well at the analytical level: they were inclusive and comprehensive when applied to the data. Consequently, the four elements were adopted as the main categories of sense of community, under which all the categories found in the data were subsumed (Figure 1).

Figure 1 approximately here

The final phase was to analyse all the categories in detail; at this point the analytical frame presented by Rogoff (1998) was applied. On the personal plane, the focus was on individual children's efforts and roles in joint activities. On the interpersonal plane, the emphasis was on the process of creating shared play activities, and on the ways and meanings of interaction. On the community/institutional plane, the context and historicity (time-span) of the social interactions in the group, the social structure of the group, its culture and how the group developed during the data collection were explored further. To enable this, the data were organised temporally, which facilitated detailed analysis of the developmental trajectories in the group. The 
role of video recordings was crucial, especially in the analysis of the interpersonal and community/institutional planes. For instance, different gestures and actions and patterns of activities present in the video material were carefully analysed. This phase of analysis was fundamental with regard to understanding the different stages and the development of the children's sense of community.

The analytical process was carefully conducted. The trustworthiness and credibility of the analysis were enhanced by means of analytical triangulation, but also by comparing different sources of data to each other. Moreover, researcher triangulation was employed. Trustworthiness and credibility were also supported by the use of examples from the data and the transparency of the description of the research process. Ethical questions were considered in connection with trustworthiness and credibility.

\section{Findings}

The examples presented here, drawn from the total set of observations, illustrate typical, frequently recurring situations that illuminate the stages and features of the development of sense of community in small groups of children, and have been translated into English post analysis.

At the beginning of August, The Raspberries group had just been formed. Only a few of the children, those who had been in the same group the previous year, knew each other. Thus, the task for both children and teachers was to get acquainted with each other. The data as a whole showed that sense of community in The Raspberries developed gradually in small groups in three successive stages: (1) laying the foundation of a sense of community through joint play, (2) creating togetherness by forming friendships and using "we-talk", and (3) establishing a sense of community in small groups The children's small group activity showed significant qualitative changes 
over time; these were manifested in their joint play, the formation of friendships, use of we-talk and establishment of strong emotional bonds with each other.

\section{Stage 1: Laying the foundation of a sense of community through joint play}

Although, from an adult perspective, membership of a peer group might be considered as something given, from the children's perspective membership turned out to be a more complex process. For them, membership meant finding one's own place in the social setting of the group and trying to consolidate friendships, actions which were at the core of this first stage of developing a sense of community. Membership presumed acceptance on the part of the other children. In practice, the children tried to find their place through joint play, which was their way of getting to know each other, and testing how successful this would be. In the following example, three four-year old girls, Mary, Lily and Ingrid, are planning a game with the cuddly toys they have brought to the day care centre from home. They were willing to let Eve join in their play, but Eve doesn't have a toy:

Mary: Does Lily have two cuddly toys for naptime?

Lily: No I don't.

Ingrid: But, hey!

Mary: But how can Eve play, then?

Ingrid: Oh, now I know. She can play with one of the day care cuddly toys!

Mary: Yes, she can play with a day care cuddly toy.

Ingrid: Yes, with that dog.

Mary, Lily and Ingrid would like to invite Eve to join their play, but they face a problem. For joint play in this particular game, a cuddly toy was a prerequisite. The girls try to solve the problem and negotiate it collaboratively. This example illustrates the role of rules in defining who belongs to the play group. Children often use objects in 
signaling their membership and identification with the group. Here, the girls try to surmount the obstacle of a missing toy for inclusion; in other cases, the absence of a suitable toy or ignorance of the specific rules of the game could be used as grounds for exclusion.

In August, and into September, as the group sought its form, the duration of joint play was often short. Children gave up play easily, as soon as any problems emerged. Disputes and conflicts were relatively common: children often tried to resolve disagreements physically, for example by hitting and pushing, instead of through verbal means. The teachers were regularly needed to resolve these conflicts. They also stressed and discussed the collective norms and rules of the group with the children. Gradually, through learning the rules and norms, getting to know each other better and by sharing good experiences in joint play, children began to form their first friendships. Slowly, the short-term testing of joint play was replaced by stable, long-term play groups, which were grounded in the children's friendships. The first friendships of the four-to-fiveyear old children were formed in October. However, among the three-year olds it was not until December that they had found friends and their own place in the group. It might be that they lacked the play and communication skills required for access to joint play and their peer culture.

In joint play, the main challenge was to gain access to the game. In some activities, such as drawing, anyone could join in, but participation in most play activities was restricted. Basically, children could choose their companions freely, but they negotiated their spaces for play with the teacher. To join a play activity, children needed good negotiation skills. These skills were also needed during play, as is evident in the next example, in which three four-year old girls, Hanna, Lisa and Tina, are starting joint role play: 
Lisa: I want to be the step-mother. Hanna will be... what do you want to be?

Hanna: What I don't want to be is Maleficient.

Lisa: I could be Maleficient.

Tina: I'll be a fairy.

Lisa: No, there is no fairy in Sleeping Beauty.

Tina: Yes, there is... the fairy Annie. Hanna can be the Sleeping Beauty, I can be the fairy.

Lisa: Okay.

Hanna: I don't want to be Sleeping Beauty. I've come up with a better game:

Cinderella.

Tina: Eeeh...okay. You (pointing to Hanna) can be Cinderella, you (pointing to Lisa) will be the evil step-mother and I will be the woodpecker.

Lisa: Aaahh...No way!

Hanna: Would it be okay, if we...if we started playing home instead...

Lisa and Tina agree.

In this example the girls were committed to playing together, but faced difficulties in determining suitable play roles. They tried to decide what to play and what their roles would be, but seemed unable to find satisfying roles for all of them. They tried to resolve the dilemma by changing the fairy tale, but this did not work either. Finally, they decided to play home and their play activity could begin. As well as negotiation skills, the example also illustrates children's togetherness and the importance of having influence on the joint activity. The children are willing to overcome every obstacle to be able to play together. The example also illustrates that having an influence on the course of the activity necessitates appropriate knowledge and social skills if their play is to succeed.

Stage 2: Forming friendships and using "we-talk" in creating togetherness 
Sense of community was first established between friends and in core groups. These first signs became visible in October, although not among the three-years olds. For the children and their integration and fulfillment of needs, the meaning of friendships was important. The children wanted to belong to a group and to do so they had to establish social relationships, preferably friendships. Friends usually wanted to play with each other and have fun together. To maintain and promote their friendships, the children used different strategies. These included addressing each other as friends, recollecting their previous play experiences, showing physical affection for each other, helping each other and creating shared routines and interactions in play. In the next example, two five-year old boys, Simon and Jake, reminisce while building a house with toy blocks:

Simon: Is it okay, if... this is the balcony, okay?

Jake: This will be a proper house.

Simon: Isn't it so that this will be the balcony, since there are steps here?

Jake: No.

Simon: [And] what then?

Jake: This will be the terrace.

Simon: Aah, It's that high, is it?

Jake: Yeah, right.

Simon: Up to this shelf, right? Right?

(...)

Simon: Oh, do you remember when we made that ship the other day, the ship which can go in the water?

Jake: Yes, we must do that again!

Simon: If [only] we could remember what it was like? Right?

Jake: It was something like this...

As Simon and Jake negotiate over the building of their house, they start talking about their past play experiences. The boys recall their shared history of play and in doing so they strengthen their friendship. Jake gets excited by the memory of the ship 
and wants to build it again. Simon agrees, but cannot remember exactly what it was like. Jake starts to describe the ship as their ongoing play continues.

The Raspberries also contained a core group of four boys that was formed during this second stage of developing sense of community. The group comprised the two five-year old boys from the previous example, Simon and Jake, together with Luke and Mark. This core group was grounded in friendship, common interests, shared history and mutual affection, and was highly cohesive. Participation in joint play and positive relationships were important for the boys. They had known each other the previous year, and were now able to further consolidate their friendship. For instance, they used 'English-like' words in their play, which the other children couldn't understand and which made it difficult for others to join them in their play. The existence of this core group was evident to the other children. The other boys wanted to join this core group, but were not accepted. Despite this, the other boys looked up to Simon, Jake, Luke and Mark and seemingly wanted to be best friends with them.

In this second stage of developing sense of community, the most significant feature was 'we-talk'. When sense of community began to evolve, children no longer referred to themselves as 'I' in joint play, but instead, both to themselves and the play group, as 'we'. The purpose of 'we' was multifaceted and it was used, for example, to refer to their previous shared history, to promote friendships and membership in the group, strengthen mutual emotional bonds, advance joint play and add commitment to shared activity. In the next example, three members of the core group Mark, Simon and Luke, are playing pirates:

Luke: Aren't there the sort [of pirates] who always sing?

Simon: Do you mean these [pirate figures] here?

Luke (pointing to the figures): No, I mean these. 
Mark (shouting): You're not allowed to touch them [pirate figures]! Those are ours [Mark's and Simon's]!

Luke (shouting): I'm part of your group!

[silence]

Luke: Hey, wait a bit, I'll get a bit bigger crocodile for this [pirate]. (...)

Mark: Ok. We could do just one crocodile, okay?

Luke: Okay. We want it to be big like this.

Simon (enthusiastically): Hey, the big one kills, doesn't it?

Mark, Luke and Simon had formed a tight-knit core group together with Jake. In this example Mark denies Luke's access to the pirate figures, saying that they belong to him and Simon. For Luke, this comes as a shock, since he and Mark were really the best of friends. Luke protests loudly and announces his belongingness to the group. He resolves the conflict by fetching another toy to play with and advance the joint script of the game. To further strengthen their group, the boys start to use we-talk towards the end of the episode (“Ok. We could do just...”). The function of we-talk was dual. First, it manifested the emotional connectedness and friendships of the boys. Second, the use of we-talk strengthened their togetherness and commitment to joint play.

\section{Stage 3. Establishing sense of community by strong emotional bonding}

This third and final stage of developing sense of community, which emerged first between friends and in the formation of core groups, and subsequently in stable play groups, occurred in March in the whole group. Positive friendships significantly contributed to the development of sense of community, as did success in joint play, which contributed to the development of togetherness and in turn to the consolidation of friendships. A manifestation of sense of community was that it did not involve friends 
alone: friends were willing to allow others to join their play, and in this way the children's play transitioned from dyadic play to group play. The next example is a continuation of an earlier situation in which dyadic play involving Simon and Jake, had become group play when they had allowed Ingrid and Lars to join them. At that point, all four children decided to engage in joint play with toy cars and a Lego house, which they continued for 20 minutes. Now, three weeks later, the same four children decide to continue the game and build a Lego house together:

Luke: Now I know! Let's do a house like this!

Lars: Let's build a wall here.

Ingrid: Hey, shall we do that big house with cars here?

Lars: Yeah. Let's do it here.

Ingrid: We can put it here and then it will be ours.

(...)

Jake: Lars, can you bring that base here.

Simon: Bring the base here, bring the base here [singing].

Simon: It will be a big house.

Jake: Hey, I know how to start it. Look... like this.

Lars: First we put there... [Lars does not finish the sentence]

Ingrid: Jake, why don't we do a fence over there from these blocks?

(...)

Ingrid: But where's that red one [block] that doesn't have any door? It could be their microwave oven.

Jake: No, it'll be their oven.

Ingrid: Well...

Mary comes along and expresses a wish to join the play. Jake refuses to allow her access.

Ingrid: I can still play here Jake, can't I?

Jake: Yes, you can.

Ingrid: But can Mary play with us? [Ingrid and Mary are friends]

Jake: No, she can't.

Ingrid: Oh, she can't... 
$(\ldots)$

Ingrid: Lars, are you playing or helping us?

Lars: Okay, I'll help. Where do these [blocks] go?

This example describes the continuation of a successful game. Simon, Jake, Ingrid and Lars have experienced togetherness in their play already previously and found it satisfying. Usually, Luke, Mark, Simon and Jake formed the core group and played together. Due to the togetherness experienced with Ingrid and Lars earlier, Simon and Jake want to share their play with them again. The children start to plan the set-up of their play and play begins. A little later, as the play is continues, Mary comes into the room and wishes to join the game. Jake, the leader of the game, refuses her request. Mary had not participated in the earlier game and Jake does not want her to join in now.

Ingrid and Mary are friends and Ingrid wants to confirm whether she is still a member of the group. She asks if Mary can join too. Jake again refuses to allow Mary access. Ingrid decides to continue her game with the boys. Jake's answer does not satisfy Mary, who goes to tell the teacher that she is not allowed to play. According to the group rule, everyone must be allowed to join in play if they so wish. Later, with help from the teacher, Mary gains access to the play.

The above excerpt illustrates how a minor conflict is resolved with the assistance of the teacher. Gradually, alongside the development of sense of community, children's mutual help increased and tensions, disagreements and conflicts, which were more frequent in the two earlier stages, were minimised. The children also displayed a great deal of positive feedback to each other which helped them to strengthen their friendships. 
Emotionally, in this final stage of development, sense of community included affective and physical closeness, sharing and caring, a feeling of belongingness and the expression of positive affects towards each other; in short, a shared emotional connection. The next excerpt illustrates the process of emotional bonding between Simon and Luke, members of the core group, when they meet each other in the morning:

Luke enters the day care centre. It is breakfast time. Simon is already having his breakfast. Luke goes to his own seat and starts eating as well. Simon doesn't say hello to Luke. They sit together at the table in complete silence, not saying a word. Simon stops eating and seems to think of something. Luke tells Simon to go on eating. When Simon has finished, they stand up and without a word go and start playing together. Later, when it is time for the morning circle, they sit side by side on the bench, arms around each other's shoulders.

This example manifests the nature of Simon's and Jake's friendship and their affective and physical closeness. The boys' silence seems a bit odd, since they were usually constantly interacting verbally with each other. However, their silence does not diminish the fact that they are continuously aware of each other and observe one another's behavior. They seem not to need words or gestures to initiate their play. Somehow they just know that after breakfast they will start playing together. Thus, their intentions are communicated in a way that does not admit outsiders. In the last part of the episode, their strong emotional bond is made clear to everyone, as they have arms their around each other's shoulders.

\section{Discussion}

Sense of community was slow to evolve in The Raspberries. It took roughly three months to achieve the first stage and another five months to reach the second stage in 
the development of sense of community. At this point, the children had established their membership of the group, formed stable friendships and begun to signal their togetherness and belongingness by using we-talk during their play. In the third and final stage, sense of community was fully established. This stage lasted until June, when the children's summer vacations began, after which the five-year olds started their preschool class in another group. By the end of the third stage children had achieved emotional connectedness and had bonded.

Pedagogically, the slowness of the process of developing sense of community needs to be considered. It is important that teachers support children's peer group processes over a long period of time, even in cases where a peer group seems to function well and all the children are included in play. The development of emotional connectedness takes time; in the present day care group this happened only after the children had been engaged in joint play for several months. Another pedagogical point to consider is related to the structure of a child group. Frequently, changes in the group occur during the day care year; for instance, some children move away and new ones join the group, while the teachers themselves might also change. This necessitates careful reflection on how to secure the inclusion, membership and shared emotional connection of all the children, irrespective of the changes that may occur, and facilitate these processes.

Friendships and participation in joint play formed the basis for the development of sense of community (Fernie, Kantor, and Whaley 1995). In addition interaction (especially we-talk) and togetherness seem to be prerequisites of sense of community. The children's we-talk served two main purposes. First, it manifested commitment and investment in joint play. Second, it strengthened their mutual belongingness. Therefore, we-talk is closely linked to togetherness and children's mutual solidarity in their peer 
group and their group identity. Sense of community was manifested in practice as strong commitment to joint play and the effort to persevere with joint play despite possible obstacles. Consequently, sense of community can be seen to be closely linked to the feeling of togetherness (van Oers and Hännikäinen 2001). All in all, it is through friendships, participation, we-talk and togetherness that children achieve emotional bonding and develop a sense of community with each other. Theoretically, these key features of sense of community can be juxtaposed with the four elements proposed by McMillan and Chavis (1986), namely membership, influence, integration and fulfilment of needs, and shared emotional connection. These four elements of sense of community are inseparably and in complex ways interconnected, but as we discussed in the theoretical framework, despite their connectedness, they are all differently manifested in the peer group. Consequently, to gain deeper understanding of the elements of sense of community, they need to be explored individually.

Membership (McMillan and Chavis 1986) in the present example was manifested in the feeling of belonging to the group. Belonging necessitated gaining access to joint play, which then enabled children to participate, form friendships and construct togetherness, which was then maintained and strengthened in joint play. The processes of constructing membership are linked to the interpersonal plane of sociocultural activity (Rogoff 1998). At the same time, on the community/institutional plane the children, together and with the teachers, were learning the rules and norms of the group (Hännikäinen 2005). As Rogoff (1998) states, it is essential to acknowledge the mutual interconnectedness and constitution of personal, social and cultural processes, while also allowing for the influence of the individual child on the peer group culture through participation in its practices. 
In addition to gaining access to and participating in play, the children clearly found it important to influence (McMillan \& Chavis 1986) their joint activities (personal plane) and each other and to give and receive positive feedback. Still, it is necessary to view interpersonal influence as a reciprocal phenomenon. Influence was not only manifested on the interpersonal plane, but also on the community/institutional plane through rules, norms and culture (Rogoff 1998).

With regard to the integration and fulfilment of needs (McMillan and Chavis 1986), participating and succeeding in joint play and collaboration was essential and promoted the feeling of togetherness. Children helped and encouraged each other in many ways and through group membership, friendships and participation their needs were met on both the personal and interpersonal planes. For children, intimacy and affective closeness were important. In addition, humour and having fun together promoted feelings of belongingness, togetherness and mutual affection (see Hännikäinen and van Oers 1999).

The above-mentioned aspects of integration and fulfilment of needs are also linked to shared emotional connection (McMillan and Chavis 1986), which was grounded in reciprocal interaction, shared experience, and participating in joint play. The children were committed to investing in their joint play and setting their own interests aside for the benefit of their collaborative efforts. Having a shared emotional connection contributed to the children's finding their joint play meaningful, important, pleasurable, and rewarding, which resulted in the development of togetherness on the personal, interpersonal and community/institutional planes. Furthermore, shared emotional connection offered possibilities to expand children's network of social relations. 
Alongside dyadic friendships, children also played in small groups. The children were often willing to allow access to others in even the most stable play groups, as the findings on the boys' core group illustrate. However, this did not diminish the significance of friendships. Based on earlier studies on friendship in the school context (e.g. Schmuck and Schmuck 1997), we know that friendship relations are linked with group cohesion which, in turn, is a manifestation of sense of community. In this study, children who were friends with each other also played in different small groups, which in turn interacted with each other thereby contributing to a collective sense of community. Thus, the larger peer group was composed of a network of mutually connected small groups indicating the presence sense of community on the collective level of The Raspberries.

The findings of this study highlight the course of events and developmental stages leading to the establishment of a sense of community in the day care setting. For children, membership of a peer group and subsequently of a community is a process that takes time. Pedagogically, it is important that teachers support the development of children's friendship relations and play skills and so help to advance the establishment of sense of community. Previous research has indicated that teachers have an important role in promoting and facilitating the development of children's sense of community in the school context (Amio 2005) and feelings of togetherness in preschool, especially when a new group starts in a day care centre (e.g. Hännikäinen 2003). In the present study, however, the focus was solely on children's perspectives, the teacher's role in the development of sense of community remained unexplored. In this study, the data were collected during free play, where the teachers had little visible input. The researcher witnessed the role of the teacher as a builder of sense of community, especially during whole group activities, such as circle times and other whole group sessions. Thus, we 
acknowledge the importance of the teacher in establishing the rules, norms and courses of activities in the group. Given that the research aim was to explore the development of sense of community at the group level, the perspective of individual children and their contribution to the development of sense of community remained unexamined. It would be important to address these issues in the future.

The theoretical and methodological implications of this study include recommending adoption of the elements of sense of community proposed by McMillan and Chavis (1986) in investigating early childhood education settings and young children's peer culture. Previously, the elements of sense of community have mainly been explored by quantitative methods to the relative neglect of a qualitative approach. This study contributes to the literature by describing the process of constructing sense of community in practice, from the perspective of children. In addition to capturing children's experiences, the qualitative method enabled detailed analysis and exploration of the features of sense of community. Yet, the fact that the findings concern only the interconnectedness of these key features in developing sense of community can be seen as a limitation. These phenomena and processes need to be elaborated and explored further.

The notion of sense of community seems to be important to children in many ways, especially emotionally and with regards to peer group membership and belongingness. Sense of community seems to contribute to a good atmosphere in the peer group, as also do inclusion, caring, and togetherness. From a sociocultural perspective, we would emphasise that friendships, joint play and emotional bonding are at the heart of young children's sense of community. However, the establishment of these elements should also be regarded as a learning process (Rogoff 2003), not only 
from the perspective of individual children, but also from viewpoint of the peer group community.

\section{References:}

Amio, J. L. 2005. Understanding children's sense of community in school: A mixed methods approach. $\mathrm{PhD}$ thesis. Department of Human Development and Applied Psychology. Ontario Institute for Studies in Education of the University of Toronto. Accessed 13.08.2015. http://search.proquest.com/docview/276427226/fulltextPDF?source=fedsrch\&ac countid=136582http://search.proquest.com/docview/276427226/fulltextPDF?sou rce $=$ fedsrch\&accountid $=136582$.

Bath, C. 2009. Learning to belong. Exploring young children's participation at the start of school. Oxon: Routledge.

Bell, N. 2008. "Ethics in child research: rights, reason and responsibilities." Children's Geographies 6 (1): 7-20. doi: 10.1080/14733280701791827.

Bess, K. D., A. T. Fisher, C.C. Sonn, and B. J. Bishop. 2002. "Psychological sense of community: Theory, research and application." In Psychological sense of community. Research, applications and implications, edited by A. T. Fisher, C.

C. Sonn \& B. J. Bishop, 3-22. New York: Kluwer Academic/Plenum Publishers.

Corsaro, W. A. 2003. We're friends, right? Inside kids' culture. Washington: Joseph Henry Press.

Corsaro, W. A. and Molinari, L. 2000. "Priming events and Italian children's transition from preschool to elementary school: Representations and action." Social Psychology Quarterly 63 (1): 16-33.

Corsaro, W. A., Molinari, L., Gold Hadley, K. \& Sugioga, H. 2003. "Keeping and making friends: Italian children's transition from preschool to elementary School.” Social Psychology Quarterly 66 (3): 272-292.

Dockett, S., Einarsdottir, J., and Perry, B. 2009. Researching with children: ethical 
tensions. Journal of Early Childhood Research 7 (3): 283-298.

doi: 10.1177/1476718X09336971

Dockett, S., E. Kearney, and B. Perry. 2012. “Recognising young children's understandings and experiences of community." International Journal of Early Childhood 44 (3): 287-305. doi: 10.1007/s13158-012-0073-y.

Engdahl, I. 2011. "Toddlers as social actors in Swedish preschool”. Doctoral thesis. Stockholm University, Faculty of Social Sciences, Department of Child and Youth Studies. Accessed 25.2.2016. http://www.divaportal.org/smash/get/diva2:391762/FULLTEXT01.pdf

Fernie, D. E., R. Kantor, and K. L. Whaley. 1995. "Learning from classroom ethnographies: Same places, different times.” In Qualitative research in early childhood settings, edited by J. A. Hatch, 155-172. Westport: Praeger.

Fleer, M. 2006. The cultural construction of child development: creating institutional and cultural intersubjectivity. International Research Journal of Early Years Education, 14, 127-140. doi: 10.1080/09669760600661294.

Greve, A. 2009. "Vennskap mellom de yngste barna i barnehagen.” Nordisk Barnehageforskning 2 (2): 91-98.

Hay, D. F., A. Payne, and A. Chadwick. 2004. Peer relations in childhood. Journal of Child Psychology and Psychiatry 45 (1), 84-102. doi: 10.1046/j.00219630.2003.00308.x.

Hedegaard, M., K. Aronsson, C. Højholt, and O. Skjær Ulvik. 2012. "Introduction.” In Children, childhood and everyday life. Children's perspectives, edited by M. Hedegaard, K. Aronsson, C. Højholt \& O. Ulvik, vii-xii. Charlotte: Information Age Publishing.

Howes, C. and L. Lee. 2007. "If you're not like me, can we play? Peer groups in preschool." In Contemporary perspectives on social learning in early childhood education, edited by O. N. Saracho \& B. Spodek, 259-277. Charlotte: Information Age Publishing. 
Højholt, C. 2012. "Communities of children and learning in school. Children's perspectives." In Children, childhood and everyday life. Children's perspectives, edited by M. Hedegaard, K. Aronsson, C. Højholt \& O. Ulvik, 199-215. Charlotte: Information Age Publishing.

Hännikäinen, M. 2003. "Transition to school in Finland: From early childhood and preschool education to basic education." In Early childhood education in five Nordic countries, edited by S. Broström \& J. Wagner, 77-99. Århus: Systime.

Hännikäinen, M. 2005. "Rules and agreements - And becoming a preschool community of learners.” European Early Childhood Education Research Journal 13 (1): 97-110. doi: 10.1080/13502930585209581.

Hännikäinen, M. 2007. "Creating togetherness and building a preschool community of learners: The role of play and games." In Several perspectives on children's play, edited by T. Jambor \& J. V. Gils, 147-160. Antwerpen and Apeldoorn: Garant.

Hännikäinen, M. and B. van Oers. 1999. "Signs and problems of togetherness in a community of learners.” Eric Document, ED 436241. Accessed 23.3.2015. http://files.eric.ed.gov/fulltext/ED436241.pdf.

Hännikäinen, M. and H. Rasku-Puttonen. 2010. "Promoting children's participation: the role of teachers in preschool and primary school learning sessions." Early Years: An International Research Journal 30 (2): 147-160. doi:

$10.1080 / 09575146.2010 .485555$.

Joerdens, S. 2014. “'Belonging means you can go in': Children's perspectives and experiences of membership in kindergarten." Australasian Journal of Early Childhood 39 (1): 12-21.

John-Steiner, V. \& H. Mahn. 1996. "Sociocultural approaches to learning and development." Educational Psychologist 31 (3-4): 191-206. doi: 10.1080/00461520.1996.9653266. 
Kantor, R., P. Elgas and D. E. Fernie. 1993. "Cultural knowledge and social competence within a preschool peer culture group." Early Childhood Research Quarterly 8 (2): 125-147. doi: 10.1016/S0885-2006(5)80087-0.

Kernan, M., E. Singer, and R. Swinnen. 2011. "Introduction.” In Peer relationships in early childhood education and care, edited by M. Kernan \& E. Singer, 1-14. Milton Park: Routledge.

Koivula, M. 2010. Lasten yhteisöllisyys ja yhteisöllinen oppiminen päiväkodissa. [Children's sense of community and collaborative learning in a day care centre] Jyväskylä Studies in Education, Psychology and Social Research, 390. Jyväskylä: University of Jyväskylä.

Ladd, G. W. 2005. Children's peer relations and social competence: a century of progress. New Haven: Yale University Press.

Lewis, C., P. Enciso, and E. B. Moje. 2007. "Introduction: Reframing sociocultural research on literacy." In Reframing sociocultural research on literacy. Identity, agency and power, edited by. C. Lewis, P. Enciso \& E. B. Moje, 1-11. Mahwah: Lawrence Erlbaum.

Linehan, C. and J. McCarthy. 2001. "Reviewing the 'community of practice' metaphor: An analysis of control relations in a primary school classroom.” Mind, Culture, and Activity 8 (2): 129-147. doi: 10.1207/S15327884MCA0802_02.

Løkken, G. 2000. “Tracing the social style of toddler peers”. Scandinavian Journal of Educational Research, 44 (2): 163-176. doi:10.1080/713696668.

McMillan, D. W. and D. M. Chavis. 1986. "Sense of community: A Definition and theory." Journal of community psychology 14: 6-23. doi: 10.1002/15206629(198601)14:1<6::AID-JCOP2290140103>3.0.CO;2-I.

van Oers, B. and M. Hännikäinen. 2001. "Some thoughts about togetherness: an Introduction.” International Journal of Early Years Education 9 (2): 101-108. doi: $10.1080 / 713670686$. 
Over, H. 2016. "The origins of belonging: social motivation in infants and young children.” Phil. Trans. R. Soc. B 371: 20150072. doi: 10.1098/rstb.2015.0072.

Rogoff, B. 1998. “Cognition as collaborative process.” In Handbook of Child Psychology, vol 2., edited by W. Damon, D. Kuhn \& R. S. Siegler, 5th edition, 679-744. New York: Wiley.

Rogoff, B. 2003. The cultural nature of human development. New York: Oxford University.

Sawyer, K. 2001. "Play as improvisational rehearsal.” In Contemporary perspectives on play in early childhood education, edited by A. Göncü \& E. L. Klein, 19-37. New York: Guilford.

Schmuck, R. A. and P. A. Schmuck. 1997. Group processes in the classroom. Dubuque: Brown \& Benchmark.

Stratigos, T., B. Bradley, and J. Sumsion. 2014. "Infants, family day care and the politics of belonging." International Journal of Early Childhood 46 (2): 171186. doi: 10.1007/s13158-014-0110-0.

Williams, P. 2001. "Preschool routines, peer learning and participation.” Scandinavian Journal of Educational Research 45 (4): 317-339. doi: 10.1080/00313830120096743.

Williams, P., S. Sheridan, and S. Sandberg. 2014.” Preschool - an arena for children's learning of social and cognitive knowledge." Early Years: An International Research Journal 34 (3): 226-240. doi: 10.1080/09575146.2013.872605. 